\title{
Training Strategies in Small and Medium-sized Enterprises from the Perspective of Technology Innovation
}

\author{
AiYing Li (Corresponding author) \\ Lin-Yi University Shandong Lin-Yi 276005, China \\ E-mail: linq1959@163.com
}

Lin Ye

Shanxi Normal University Shanxi Lin-Fen 041004, China

E-mail: linyegreat@126.com

Received: October 18, 2010 Accepted: January 14, 2011 doi:10.5430/jms.v2n1p70

\begin{abstract}
It's very important to know the training needs of enterprise's past and present demand, training activities planning often starting to solve problems of the past and present. Based on technical innovation training, training analysis is ascending into the strategic level, standing in a new height. Through the analysis of the role which enterprise training plays in technology innovation, based on the enterprise development strategy, job analysis and technical requirements; propose technical processes in small and medium-sized enterprises. From the Angle of enterprise technology innovation, put forward the enterprise training strategies which should be adopted in small and medium-sized enterprises.
\end{abstract}

Keywords: Enterprise training, Small and medium-sized enterprises, Technology innovation, Training strategy

\section{Introduction:}

The number of small and medium-sized enterprises in China accounted for $99.3 \%$ of total national enterprises, $55.6 \%$ of national GDP, $74.7 \%$ of industrial added value, $58.9 \%$ of social sales tax, revenue 46 percent and exports $62.3 \%$ are created respectively by small and medium-sized enterprises and approximately $75 \%$ of the urban employment is provided by small and medium-sized enterprises (Li, W., andYou, J., 2007). Small and medium-sized enterprises has become an important industrial economic growth in China, has made tremendous contributions for national economy. Therefore, how to training in order to adapt to the needs of technological innovation of small and medium-sized enterprises, improve the market competitiveness and sustainable development ability, has become a vital problem.

\section{Technological Innovation Problems in Small and Medium-sized Enterprises}

\subsection{Lack of creative consciousness}

Many small and medium-sized enterprises think that technology innovation is what large enterprises and research institutes should do, the initiative is not strong. Even when they must make technical innovation, still depend entirely on government's investment and promotion, never see themselves as the subject of technological innovation. Also some small and medium-sized enterprise leaders do not realized the role which technological innovation play in enterprise competitiveness, just focus on extension of production, which restrict the further development of enterprises.

\subsection{Shortage of capital}

Lack of funds is the biggest obstacle to innovation for small and medium-sized enterprises. Many small and medium-sized enterprises don't have funds for $R \& D$ or though funding, but miserable, unable to complete the technological innovation activities. This is because the weak economic strength, financing capability, and less financing channels, on the other hand is because Small and medium enterprises do not have enough sense of innovation, there is no emphasis on technical innovation, also don't get sufficient funds carry out technical innovation. 2.3 Shortage of talent

Employed person in Small and medium enterprises mainly from surplus rural labor and urban residents newly entering the workforce, most of them are short of the job-related skills (Bi,Y., andLi,Y., 2008). The number of technical staff and managers are not sufficient and the technical level and management level is relatively low can not meet the needs of technical innovation. Small and medium enterprises are less attractive, it is difficult to attract high-quality technical personnel and managers. 


\subsection{Inadequate information}

The key to technological innovation is information which is the source of innovation. Our information infrastructure is undeveloped and the coverage of information network is narrow, with some government departments pay inadequate attention on Small and medium enterprises, because of national information policy, state-owned enterprises enjoy more information resources, so that small and medium enterprises make it difficult to obtain information from the outside. Small and medium enterprises are lack of effective supply of technology innovational information, especially technological and commercial messages. Lack of commercial information, the impact on business innovation is also extensive and profound, lack of marketable information, businesses are unable to find opportunities for innovation, can not guarantee the market prospects of innovation. Enterprises can not timely master accurate, reliable scientific information, and can't understand the latest technology and direction at home and abroad, fail to respond quickly to market.

\section{Training Needs Analysis}

\subsection{Analysis processes of technical training needs}

The traditional method of training needs put more attention on the needs of business in the past and present situation, and as the starting point to plan training activities in order to solve business problems that have accumulated over the past and the present. The training needs based on technological innovation enhance the training needs analysis to the strategic level, stands at a new level. First, the company's strategic training needs analysis is forward-looking, its decision is based on the future development needs of enterprises so as to meet needs in the market competition; Second, analysis positions based on the enterprise training needs, mainly through analysis of knowledge, skills gap state with the existing conditions which are necessary to complete the tasks of technological innovation, to determine the training courses that training needs, mainly through analysis the organization's objectives, structures, policies, performances, environmental factors, accurately identify organizational problems and the source of the problem in order to determine whether the most effective way is training; Third, analysis position technical requirements, it is useful for employees to find the gap to look for gaps, cover the shortage, fulfil the task in the way of strengthening knowledge, skills and behaviors. Its purpose is to see the performance-related working details, standards and the knowledge and skills that should have in order to complete the work, so as to design and work out the related training courses; Fourth, analysis of individual employees, from the perspective of the trainees profile training needs, by analyzing of the gap between individual employees' current condition and the condition supposed to be, determine Who Should Attend and the content. On that basis, determine the corporate training objectives. The figure 1 below based on training needs analysis shows the analysis process.

\subsection{Key links of training needs analysis}

The core of training needs analysis is to identify the gap between corporate status and objectives, technology innovation strategic goals, job standards, the development aspirations of individual employees, and then to analyze the reasons for the gap, find what areas can be addressed through training. For this, firms should have to grasp the key link of training needs analysis: a) Make each employee understand the technological innovation strategy, realize the relationship between their work and enterprise development strategies; b) Before carrying out training needs analysis, it is vital to create an environment within the enterprise, so that the business leaders, branch manager, project managers, "the five members', engineers and operators all have psychological preparation and time to think about themselves, the department, the project Department, the company's training needs, causing the attention of each person; c) Based on performance- assessment, analysis of performance goals and gaps, for those who fail to complete performance goals, we must analyze carefully, is it the skill factors or ideological factors, if they are caused by skill factors, it should be solved through training which produced a training needs; d) The effectiveness training needs analysis should be guaranteed by a whole work processes, therefore, firstly determine the time and the main task of the whole analysis process, make complete plans and programs, gain the approval from relevant persons, secondly, design related forms, analysis models, in advance to verify the effectiveness of tools; e) When use of models, according conditions and flexible use of it.

Through training needs analysis, you can understand the training needs in enterprises; also understand the training needs of the staff. According to the technological innovation strategy, which combined the above two desires, determine long-term training needs of business and annual training needs, for the training plan and training programs.

\section{Technology-based Innovation Strategy for Small and Medium Enterprises Training}

If small and medium enterprises establish their own training institutions, training costs is relatively high; therefore, companies rely mainly on external training resources, see internal training resources as supplement. According to the requirements of technological innovation on different levels of staff, firms should target to different training strategies. 


\subsection{Conduct training for companies' technological innovation in senior management, for the creative consciousness}

Through different levels of training, Small and medium enterprises should be aware of technological innovation is not only big companies or research institutions should do but also ways to accelerate development of Small and medium enterprises, achieve business objectives. First foster awareness of innovation, put technology innovation activities in the business agenda, firmly establish the technology innovation is an effective ways to development, not just "wait ,rely on and ask for", firms can not promote and support by government alone, they should take the initiative to engage in technological innovation, rather than passively waiting, make small and medium enterprises truly become the main body of technological innovation, second is to establish an effective training system and in accordance with strategic development objectives, develop medium and long term corporate training program.

4.2 Introducing competency models to meet training needs of different levels and the different types of staff within the enterprise

"Competence" in this context emphasizes the values of workers, motivation, personality or attitudes, skills, knowledge and other characteristics; it is closely linked with job performance, it can be used to predict future performance; it can distinguish outstanding and ordinary performance. Competency model is combined with required superior performance in one position, contains multi-competence structure, which "describes an unique combination of specific knowledge, skills and characteristics to efficient complete the work". (Bi, Y., andLi, Y., 2008). In small and medium enterprise, training can force this model as the training content, training design. In particular, for small and medium enterprises, the enterprise can build competence in various key positions in the model to determine the employees' values, motives, personality or attitudes, skills, knowledge management research.

\subsection{Develop training mode for social training}

By the intermediary institutions and civil society groups, provide training for Small and medium enterprises, There are two ways for their training, one is enterprises and institutions take training together, staff in the firm are in the common with rich experience, but lack of theoretical knowledge, teaching method does not flexible, people in professional training institutions are always theory knowledgeable instructor, teaching in a higher level, but can not combine the reality of the enterprise production and operation of the phenomenon together, the right thing is integrate them, complementary, enhance training effectiveness; second is Heuristic self-training, it is a self-learning activities for obtaining some professional academic and technical qualifications which countries have set up, participate in agency training institutions to get a professional qualification certificates ,enterprise support for their positive attitude, and set up assistance system.

\subsection{Introduction of modern learning theory, and Suitable teaching model(Song, H., 2007),improve training methods}

In training design and training effectiveness evaluation process, we can accord to different learning characteristics design scientific training methods to improve the training processes and methods in small and medium enterprise. Against the characteristics of persons in different posts, training priorities and characteristics of trainees, make trainees actively participate in training and learning activities. Through multimedia, Internet, games, scenario exercises, group discussions, case teaching and other new technologies and new methods to improve and enhance the existing Small and medium enterprises internal and external training effect. 4.5 Establish and improve the training management system

Training effect in Small and medium enterprises can not achieve without a sound training management system. In particular, our Small and medium enterprises can try the following three works. a) Establish training funds management system; b) Establishing training incentive system, improve the incentive mechanism to mobilize the enthusiasm of the trainees; c) Enhance the training quality control and establish a strict system of training quality assessment.

\subsection{Adhere to good internal training}

Internal training can be designed according to different learning characteristics, improve the training processes and methods in small and medium enterprises, according to characteristics of different positions, training priorities and the characteristics of trainees, enable trainees to actively participate in training and learning activities. The Government should also encourage and support small and medium enterprise independently training in enterprises, actively implement staff training programs, at the same time, improve the quality of regional labor and industry. The Government should continue to improve the system environment, the incentive to develop workable self-training policies for Small and medium enterprises. 


\section{References}

Li, W., andYou, J. (2007).Experience of Training System in Foreign SMEs.Business Times,29 pp:54-55.

Bi, Y., andLi, Y. (2008).Training Problems and countermeasures for small and medium enterprises in China. Management.

Song, H. (2007). Corporate continuing education deconstruction of modern learning theory. Modern business education.6 Chapter8.

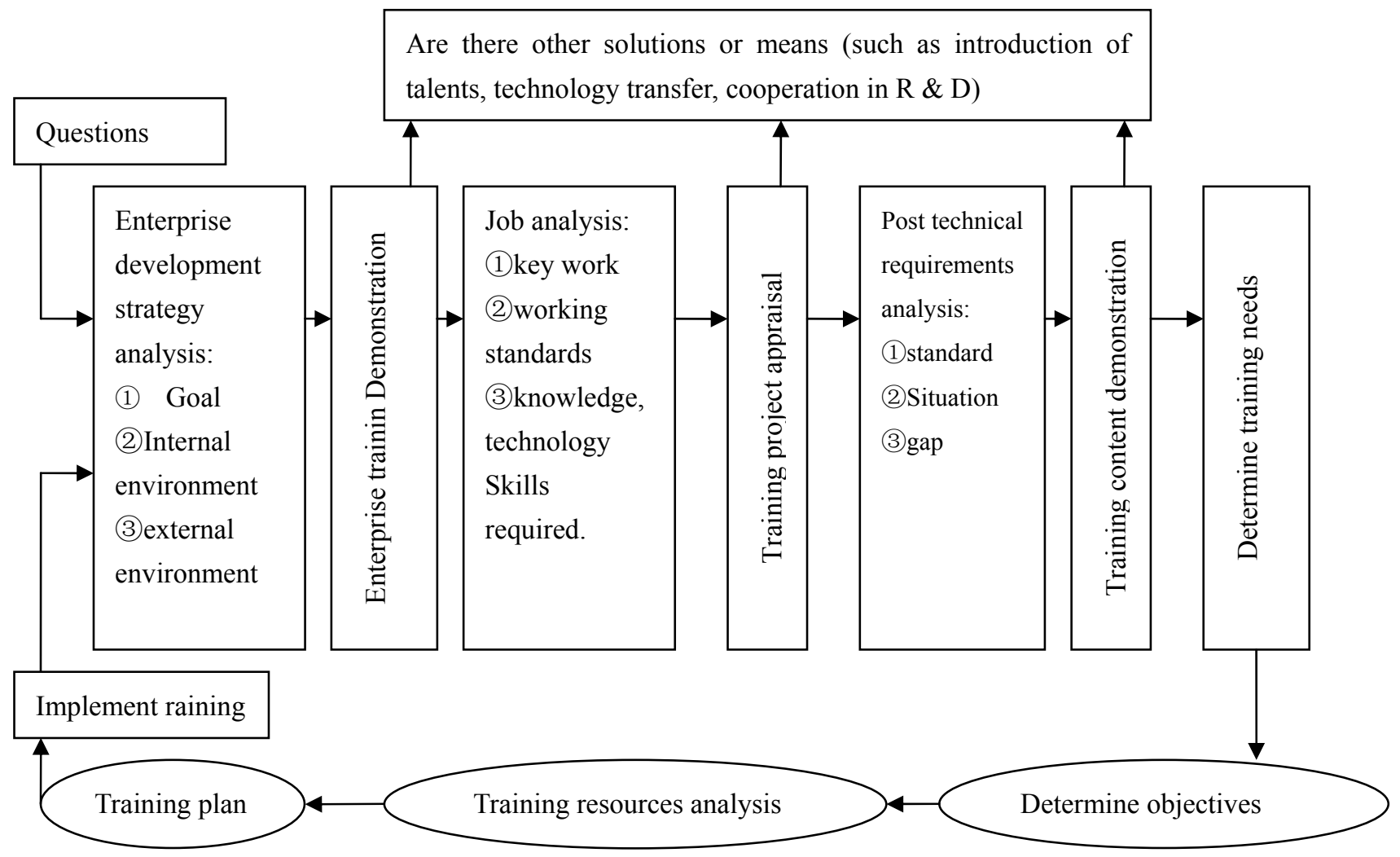

Figure 1.The chart of training needs 